\title{
EFEITO ALELOPÁTICO DE EXTRATOS DE CARQUEJA (Baccharis trimera) E CONFREI (Symphytum officinale) EM SEMENTES E PLÂNTULAS DE GIRASSOL
}

\author{
A llelopathic effect of the carqueja (Baccharis trimera) and omfrey \\ (Symphytum officinale) ex tract on sunflower seeds and seedlings
}

\author{
Allyson Gomes da Silva ${ }^{a}$, Ruy Inácio N eiva de Carvalho ${ }^{\mathrm{b}}$ \\ a Engenheiro Agrônomo, São José dos Pinhais, PR - Brasil, e-mail:allyson.silva@ uol.com.br

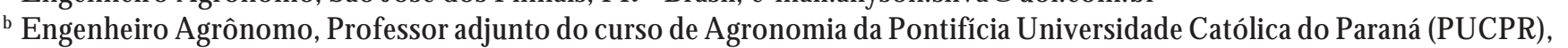 \\ São José dos Pinhais, PR, Brasil, e-mail: ruy.carvalho@ pucpr.br
}

\begin{abstract}
Resumo
O presente trabalho teve como objetivo avaliar o efeito alelopático da carqueja e confrei sobre a germinação de sementes e crescimento inicial de girassol. O s experimentos foram realizados em casa de vegetação e em Laboratório de Análise de Sementes, onde o extrato bruto aquoso (EBA) das duas plantas foi estudado em diferentes concentrações $\left(0,50,100,150,200\right.$ g.L $\left.\mathrm{L}^{-1}\right)$ aplicadas no substrato ou no papel de germinação com cinco repetições. O EBA foi obtido por turbilhonamento das plantas medicinais em liquidificador $\left(200\right.$ g. $\left.\mathrm{L}^{-1}\right)$ e depois diluído com água destilada para obtenção das demais concentrações. No tratamento em casa de vegetação cada parcela foi formada por 10 sacos para mudas totalizando 250 embalagens regadas com $70 \mathrm{~mL}$ do extrato na semeadura e dois dias após com mais $35 \mathrm{~mL}$ do extrato. Os tratamentos foram avaliados por 35 dias. 0 extrato bruto aquoso de confrei nas concentrações testadas não apresentou, em casa de vegetação, efeito inibitório sobre plantas de girassol, mas sim um estímulo a seu crescimento. Em laboratório, esse extrato nas concentrações até 150 g.L $\mathrm{L}^{-1}$ não apresentou efeito inibitório sobre a porcentagem de plântulas normais de girassol. $O$ extrato bruto aquoso de carqueja em concentração de 200 g.L ${ }^{1}$ promoveu atraso da emergência de plantas de girassol em casa de vegetação. Em laboratório, houve interferência do uso do extrato bruto aquoso de carqueja sobre a ocorrência de anormalidade nas plântulas de girassol, comprovando um efeito significativo, mas sem tendência definida.
\end{abstract}

Palavras-chave: Alelopatia. Plantas daninhas. H elianthus annuus. 


\begin{abstract}
This research aimed to evaluate the allelopathic effect of the aqueous extracts of the aerial part of the carqueja plants and of the entire plant of comfrey on the seeds germination and seedlings development of sunflower. The treatment adopted was composed of five concentrations of extract: 0, 50, 100, 150 and 200 g. $L^{-1}$, of plants in water. The research was carried out in the greenhouse and in the Laboratory of Seed Analysis. In the greenhouse, 10 plastic bags were used to represent an experimental plot. The soil was irrigated with $70 \mathrm{~mL}$ of the different treatments at sowing and with $35 \mathrm{~mL}$ two days later. The observations were carried out during 35 days. An inhibitory effect of comfrey extract on seeds and seedlings of sunflower in concentrations up to $150 \mathrm{~g} . \mathrm{L}^{-1}$ was not observed in laboratory. In greenhouse, this extract in all tested concentrations were favorable to seedlings development. The carqueja extract at the concentration $200 \mathrm{~g} \mathrm{~L}^{-1}$ promoted an emergency delay of seedlings in greenhouse and the occurrence of abnormal seedlings in the germination tests in the laboratory.
\end{abstract}

Keywords: Allelopathy. Weeds. Helianthus annuus.

\title{
INTRODUÇÃO
}

O girassol (H elianthus annuus L.) é uma dicotiledônea anual da família A steraceae, originária do continente Norte Americano que foi levada à Europa pelos colonizadores portugueses e espanhóis que mais tarde introduziram-na no Brasil devido ao hábito de consumo de suas sementes torradas (CA STRO et al., 1997). No Sul do Brasil, pesquisas envolvendo a cultura do girassol foram realizadas a partir de 1952 e em 1978, com o surgimento de novas cultivares, ocorreu aumento da área de cultivo no Paraná e posteriormente, no Rio Grande do Sul. Em 1996, a tentativa de expansão rápida do cultivo do girassol fracassou por causa da falta de critérios de recomendações regionalizadas (BORKET et al., 1997).

0 ciclo vegetativo do girassol varia entre 90 e 130 dias, dependendo da variedade, da data de semeadura e das condições ambientais. A competição com plantas daninhas é muito prejudicial para o cultivo do girassol e o período crítico de competição se dá nos primeiros 30 dias após a emergência, período no qual as plantas de girassol apresentam crescimento lento (CASTRO et al., 1997).

O bjetivando-se reduzir o uso de herbicidas em lavouras de girassol, em especial nesse período crítico de competição, técnicas alternativas podem ser desenvolvidas como a influência possivelmente existente entre plantas já conhecidas, cuja interação recebe o nome de alelopatia.

0 conceito de alelopatia afirma que um indivíduo influencia outro, favorecendo ou prejudicando o segundo, e sugere que o efeito é determinado por biomoléculas, denominado aleloquímico, produzidas por uma planta e lançadas no ambiente, seja na fase aquosa do solo ou substrato, ou mesmo por substâncias gasosas volatilizadas no ar ao redor das plantas terrestres. A atividade dos aleloquímicos tem sido estudada como alternativa ao uso de defensivos agrícolas seja como herbicida, inseticida ou nematicida. Essas substâncias são provenientes do metabolismo secundário das plantas pela sua evolução contra a ação de microrganismos, insetos e outros patógenos ou predadores, seja inibindo ou estimulando o crescimento e desenvolvimento das plantas (CASTRO; FERREIRA, 2001).

A rotação de cultivos é uma prática bastante usada no Brasil, a qual propicia a incorporação de restos da cultura anterior no solo, que poderão desempenhar atividades alelopáticas devido à liberação de substâncias químicas. Porém, se este efeito é prejudicial, pode haver diminuição do crescimento e produtividade (FERREIRA; ÁQUILA, 2000).

As plantas medicinais como a carqueja e o confrei, por causa da sua riqueza em metabólitos secundários, podem ser importantes fontes de moléculas com efeito inibidor sobre o crescimento de plantas invasoras.

A carqueja (Baccharis trimera Less. DC.) é planta que possui princípios ativos com várias propriedades. Em análise fítoquímica de B. trimera pode-se observar a presença de flavonoides, taninos, ácidos graxos, esteroides e/ ou triterpenoides, cumarinas, aminogrupos e traços de glicosídeos saponínicos (BONA et al., 2002). 
Efeitos alelopáticos foram observados a partir de extratos aquosos de carqueja, que retardaram a germinação de sementes de tomate, alterando o tempo e a velocidade da germinação. Isso pode ser relacionado com a presença de tanino na parte aérea da carqueja, que pode ser hidrolisável ou não-hidrolisável. O s taninos hidrolisáveis são conhecidos alelopaticamente, pois atuam como inibidores da germinação de sementes, do crescimento de plantas, das bactérias fixadoras de nitrogênio e das nitrificantes (CASTRO; FERREIRA, 2001).

Segundo D epiné (2003), o extrato da parte aérea de carqueja apresentou efeito alelopático sobre sementes de picão-preto (Bidens pilosa L.) reduzindo a porcentagem e a velocidade de germinação. $\mathrm{O}$ resíduo do extrato bruto aquoso da parte aérea de carqueja ou a planta picada, ambos aplicados em cobertura, assim como plantas incorporadas no substrato reduziram significativamente a emergência e 0 número de folhas de tiriricas (C yperaceae).

O confrei (Symphytum officinale) é uma planta da família Boraginaceae originária da Rússia e, dentre todas as plantas do reino vegetal, é a que contém maior teor de proteína. O confrei é uma planta perene, herbácea de raízes grossas, escuras, nodosas e tenras. Seus frutos são constituídos de esquizo carpos, pardo-escuros e muito pequenos, ou frequentemente atrofiados (CASTRO ; CHEMALE, 1995). 0 confrei tem como principais constituintes a alantoína, taninos, acúcares, saponinas, triterpenos, vitaminas, aminoácidos essenciais, esteroides, ácidos orgânicos, alcaloides pirrolizidínicos (sinfitina e equimidina), mucilagens e fitoesteroides (TESKE; TRENTINI, 2001).

Assim como para a carqueja, o extrato de plantas inteiras de confrei $\left(200 \mathrm{~g}^{-\mathrm{L}^{-1}}\right)$ determinou menor porcentagem de emergência de tiriricas em casa de vegetação (GAZIRI; CARVALHO, 2004).

Essas duas espécies de plantas, porém, só podem ser utilizadas para inibição de plantas invasoras num sistema agrícola se não provocarem inibição sobre as culturas de interesse. D esta forma, o desenvolvimento de pesquisas sobre a interação entre plantas trará dados complementares para 0 estudo de formas alternativas para o controle de invasoras, determinando o uso racional de herbicidas no manejo de grandes culturas como a do girassol.

O objetivo deste trabalho consistiu no estudo do efeito do uso de extratos de carqueja (B. trimera Less. D C.) e confrei (S. officinale L.) em diferentes concentrações sobre a germinação de sementes e crescimento inicial de girassol ( $\mathrm{H}$. annuus L.).

\section{MATERIAIS E MÉTODOS}

As pesquisas foram desenvolvidas no Laboratório de Análise de Sementes e na casa de vegetação da Pontifícia Universidade Católica do Paraná, Câmpus São José dos Pinhais - PR.

Os extratos brutos aquosos (EBA) foram obtidos através de turbilhonamento em liquidificador com água destilada da parte aérea de carqueja e das plantas inteiras de confrei na proporção de $200 \mathrm{~g} \cdot \mathrm{L}^{-1}$. E m seguida foram realizadas as diluições para obtenção dos cinco tratamentos nas concentrações de 0, 50, 100, 150 e 200 g.L.- ${ }^{-1}$.

No laboratório, a germinação das sementes de girassol, variedade EMBRAPA 122, foi testada pelo método do rolo de papel, com 50 sementes devidamente distanciadas sobre cada papel de germinação, embebido por imersão com as soluções de EBA e levados para câmara de germinação a temperatura de $25^{\circ} \mathrm{C}$. C ada parcela para cada uma das concentrações de carqueja e confrei foi composta de dois rolos de 50 sementes. Cada tratamento teve cinco repetições totalizando 25 parcelas e um total de 2.500 sementes. Os testes de germinação foram conduzidos por 7 dias quando foram avaliadas as seguintes variáveis: plântulas normais (\%), plântulas anormais (\%), sementes dormentes (\%), sementes duras (\%) e sementes mortas (\%). Os critérios de avaliação de anormalidade de plântulas foram obtidos nas Regras para Análise de Sementes (BRASIL, 1992).

Na casa de vegetação, as sementes de girassol foram semeadas em sacos plásticos (uma semente por recipiente), com um volume aproximado de $1.600 \mathrm{~cm}^{3}$, com solo regado com os cinco tratamentos com EBA de volume de $70 \mathrm{~mL}$ do extrato na semeadura e mais $35 \mathrm{~mL}$ do extrato dois dias após. Foram feitas cinco repetições e cada parcela foi constituída por 10 sacos plásticos, totalizando 250 recipientes para cada espécie estudada.

Os testes foram conduzidos por 35 dias quando foram avaliadas as seguintes variáveis: emergência (\%), altura das plantas (cm), número de folhas e massa seca $(\mathrm{g})$.

A altura das plantas e o número de folhas foram analisados a cada 7 dias. A massa seca das plantas foi determinada pela manutenção das partes aéreas das plantas em estufas de secagem a $70^{\circ} \mathrm{C}$ até massa constante. 
O delineamento experimental utilizado foi o completamente casualizado com cinco tratamentos (concentrações do EBA) e cinco repetições. As duas plantas (carqueja e confrei) foram analisadas separadamente. Os tratamentos com diferenças significativas pelo " $\mathrm{F}$ " teste da análise de variância foram submetidos à análise de regressão.

\section{RESULTADOS}

Na análise do uso do extrato bruto aquoso (EBA) de confrei sobre sementes de girassol em casa de vegetação não foi detectado efeito alelopático definido sobre a porcentagem de emergência das plantas quando comparado à testemunha (Figura 1). Ao analisar-se a altura das plantas, pode-se observar estímulo ao crescimento quanto maior for a concentração do EBA (Figura 2). Isto se confirma com a variável massa seca, pois plantas tratadas com maiores concentrações do EBA tiveram maior massa seca (Figura 3). 0 extrato não causou alteração do número de folhas da planta quando comparado à testemunha.

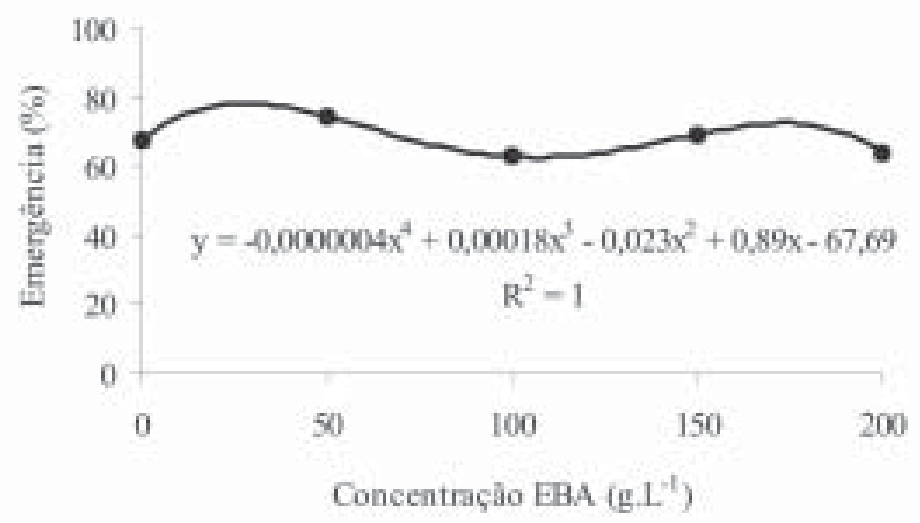

FIGURA 1 - Efeito daconcentração de extrato bruto aquoso (EBA) de confrei (Symphytum officinale) sobre a emergência (\%) de plântulas de girassol (H elianthus annuus) em casa de vegetação

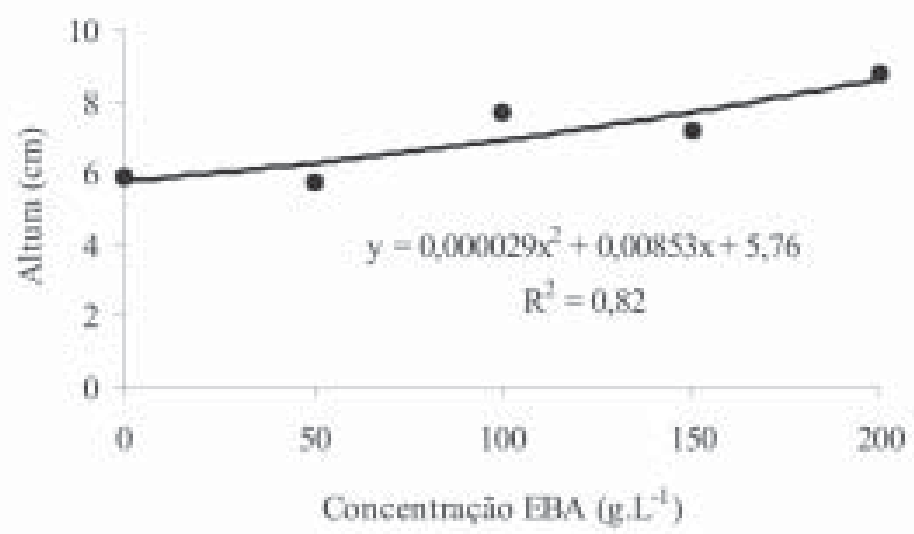

FIG URA 2 - Efeito daconcentração de extrato bruto aquoso (EBA) de confrei (Symphytum officinale) sobre a altura de plantas de girassol (H elianthus annuus) em casa de vegetação 


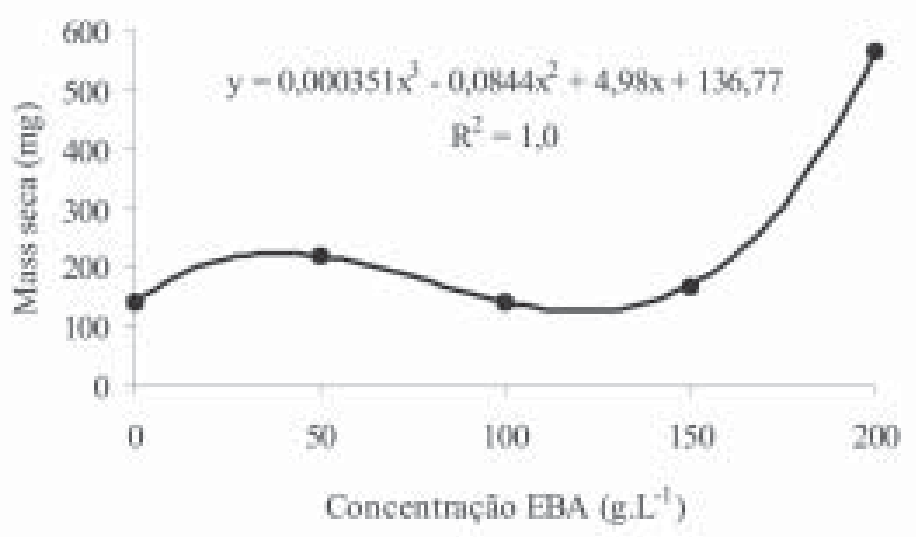

FIGURA 3 - Efeito da concentração de extrato bruto aquoso (EBA) de confrei (Symphytum officinale) sobre massa seca de plantas de girassol (H elianthus annuus) cultivadas em casa de vegetação

$O$ efeito do EBA de confrei sobre a germinação de sementes de girassol em laboratório mostrou significância estatística com relação à ocorrência de plântulas normais, pois ocorreu aumento da sua porcentagem com 0 uso do EBA até a concentração de 100 g.L.-1 (88 \%) seguido de redução até a concentração 200 g.L $\mathrm{L}^{-1}(82 \%)$ um pouco abaixo da porcentagem obtida no tratamento testemunha (84 \%) (Figura 4). Com relação às anormalidades de plântulas, observouse aumento na porcentagem de plântulas sem raiz primária, em especial quando concentrações de EBA acima de 100 g. L $^{-1}$ foram utilizadas (Figura 5). Para as anormalidades ausência de raízes secundárias, hipocótilo enrolado, sementes duras, mortas e dormentes, não houve significância estatística quando comparado à testemunha.

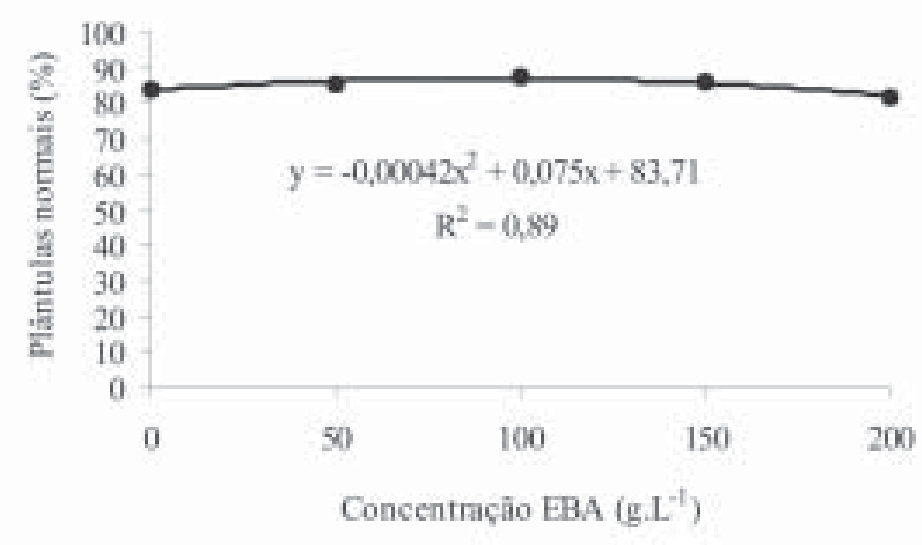

FIGURA 4 - Efeito do extrato bruto aquoso (EBA) de confrei (Symphytum officinale) sobre a porcentagem de plântulas normais de girassol (H elianthus annuus) após teste de germinação em laboratório 


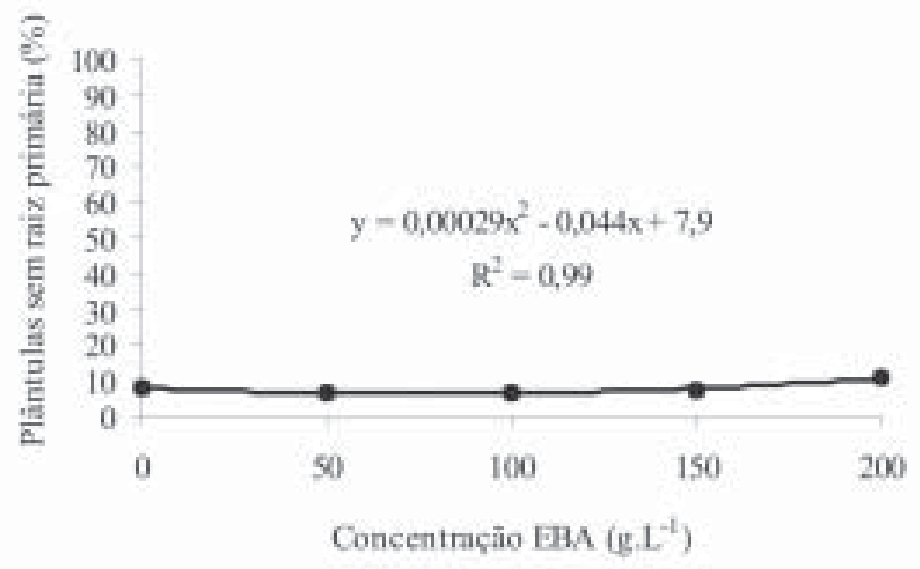

FIGURA 5 - Efeito da concentração de extrato bruto aquoso (EBA) de confrei (Symphytum officinale) sobre a porcentagem de plântulas de girassol (H elianthus annuus) com ausência de raiz primária após teste de germinação em laboratório

O extrato de plantas inteiras de confrei $\left(200 \mathrm{~g} \cdot \mathrm{L}^{-1}\right)$ já foi estudado sobre tiriricas em casa de vegetação e determinou menor porcentagem de emergência das plantas (GAZIRI; CARVALHO , 2004). Os principais constituintes da planta que poderiam estar associados a esta inibição são a alantoína, taninos, saponinas, triterpenos, alcaloides pirrolizidínicos (sinfitina e equimidina), mucilagens e fitoesteroides (TESKE; TRENTINI, 2001).

Nos tratamentos com EBA de carqueja em casa de vegetação, as concentrações até 100 g.L ${ }^{1}$ apresentaram efeito estimulador da emergência após 14 dias da instalação (Figura 6). O bservou-se que houve redução significativa da porcentagem de emergência de plântulas de girassol aos 35 dias após instalação do experimento quando utilizada a concentração de 200 g.L.-1 (Figura 7). A altura das plantas, quando comparadas à testemunha, não foi alterada pela utilização dos tratamentos com EBA. As variáveis número de folhas e matéria seca de plantas também não apresentaram diferenças significativas quando comparadas à testemunha.

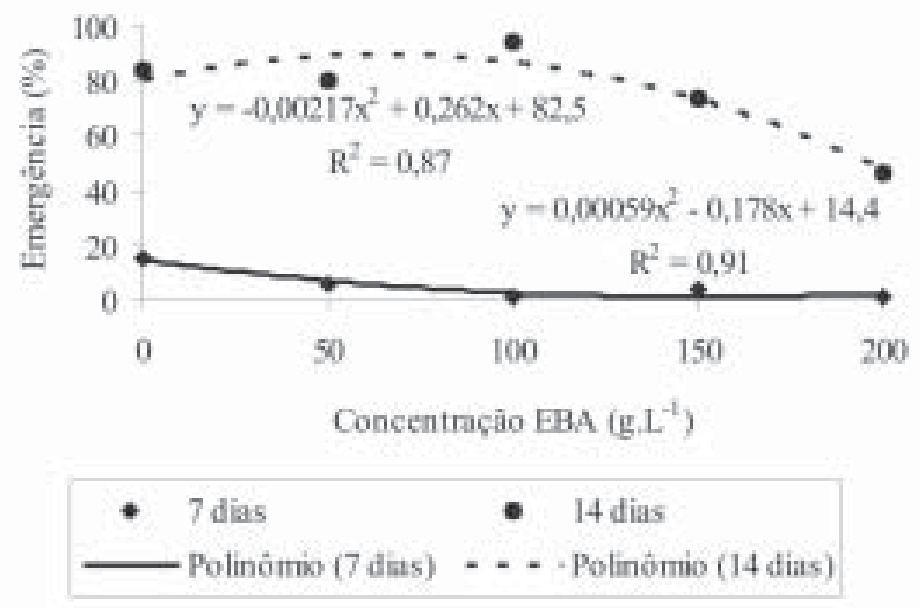

FIGURA 6 - Efeito do extrato bruto aquoso (EBA) de carqueja (Baccharis trimera) sobrea porcentagem de plântulas de girassol (H elianthus annuus) emergidas em períodos de 7 a 14 dias após semeadura em casa de vegetação 


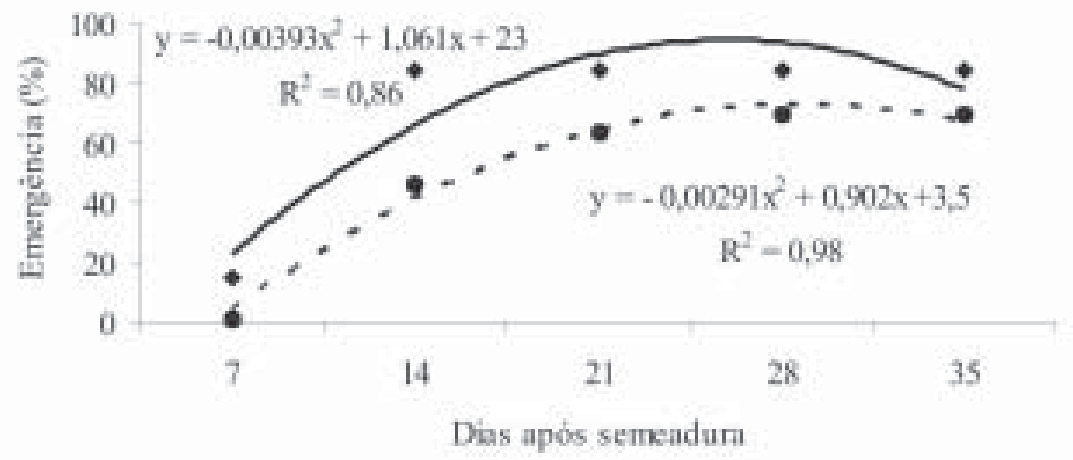

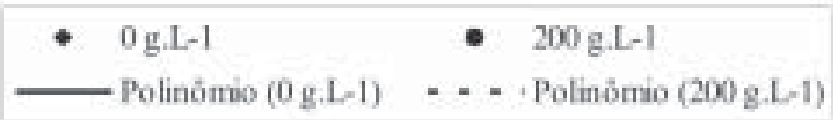

FIG URA 7 - Efeito do extrato bruto aquoso (EBA) decarqueja(Baccharis trimera) sobre a porcentagem de emergência de plântulas de girassol (H elianthus annuus) no período de 35 dias

Já em laboratório, a porcentagem de anormalidades em plântulas oriundas de sementes tratadas com EBA de carqueja foi uniforme entre as concentrações estudadas, exceto para a concentração de 150 g.L-1 , a qual provocou maior ocorrência de plântulas anormais após o teste de germinação (Figura 8).

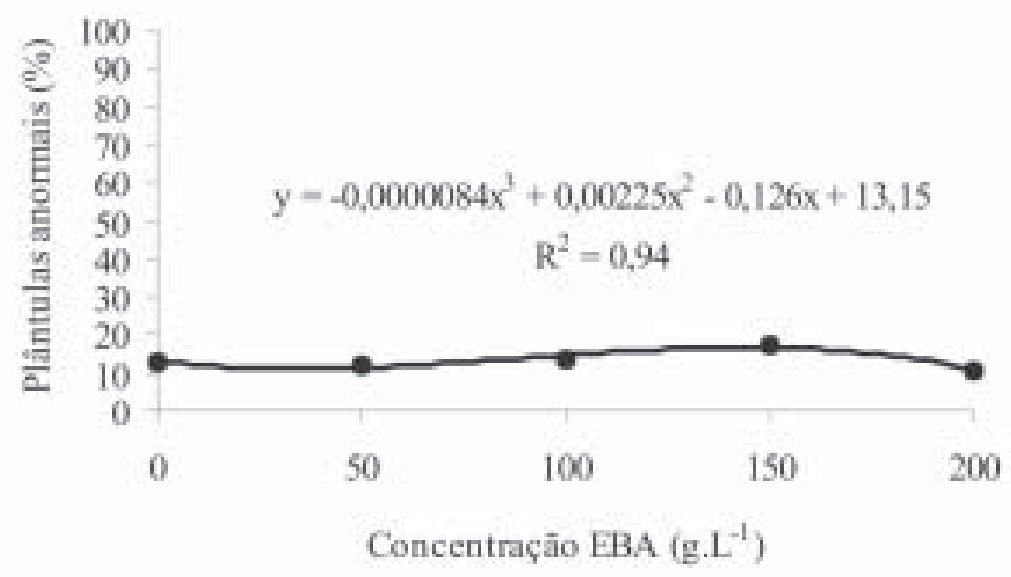

FIGURA 8 - Efeito do extrato bruto aquoso (EBA) de carqueja (Baccharis trimera) sobre a porcentagem de ocorrência de plântulas de girassol (H elianthus annuus) com anormalidades após teste de germinação em laboratório 
A porcentagem de plantas sem raiz primária foi bastante desigual nas diferentes concentrações, sem apresentar tendência clara de evolução da anormalidade em função do aumento da concentração do EBA. Na concentração de $50 \mathrm{~g} \cdot \mathrm{L}^{-1}$ ocorreu menor porcentagem de plântulas com esta anormalidade (Figura 9). Esta variação de resultados também foi observada para as anormalidades ausência de raiz secundária e plântulas com hipocótilo enrolado, porém a utilização da concentração de 50 g.L $\mathrm{L}^{-1}$ determinou maior porcentagem de ocorrência dessas anomalias (Figuras 10 e 11). Para as variáveis sementes dormentes, duras e mortas, não houve diferenças estatísticas significativas entre os tratamentos.

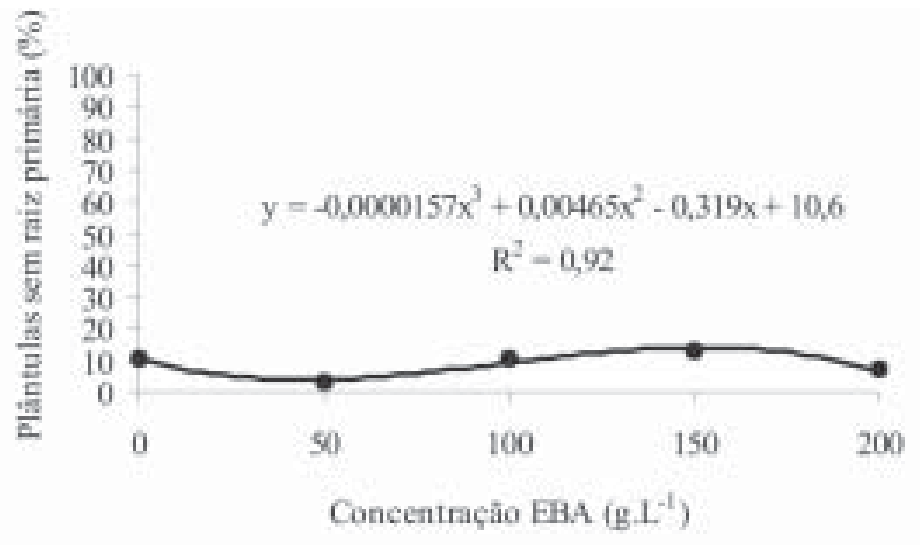

FIGURA 9 - Efeito do extrato bruto aquoso (EBA) de carqueja (Baccharis trimera) sobre a porcentagem de plântulas de girassol (H elianthus annuus) que apresentaram a anormalidade ausência de raiz primáriaapósteste de germinação em laboratório

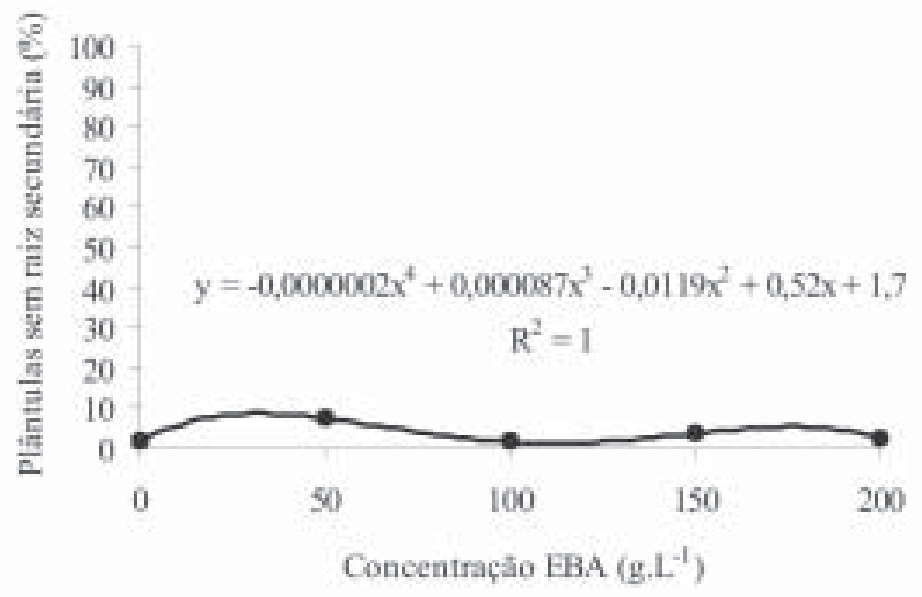

FIGURA 10 - Efeito do extrato bruto aquoso (EBA) de carqueja (Baccharis trimera) sobre plântula de girassol (Helianthus annuus), que apresentaram a anormalidade ausência de raiz secundária após teste de germinação em laboratório 


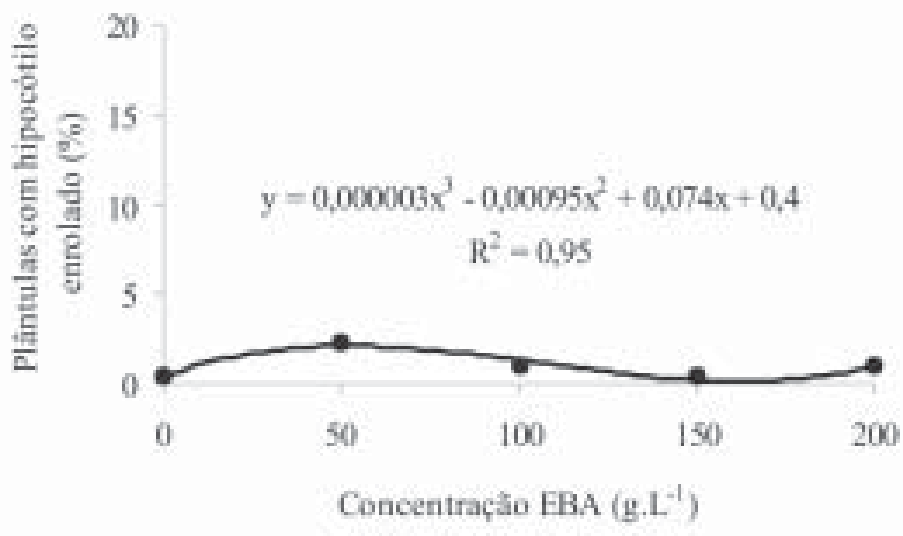

FIGURA 11 - Efeito do extrato bruto aquoso (EBA) de carqueja (Baccharis trimera) sobre plântulas de girassol (H elianthus annuus) que apresentaram a anormalidade de hipocótilo enrolado após teste de germinação em laboratório

O efeito alelopático de extratos de carqueja já foi constatado em sementes de picão-preto (Bidens pilosa L.), reduzindo a porcentagem e a velocidade de germinação (D EPINÉ , 2003). Esse efeito pode ser relacionado com a presença de tanino na parte aérea da carqueja que pode ser hidrolisável ou não-hidrolisável. O s taninos hidrolisáveis são conhecidos alelopaticamente, pois atuam como inibidores da germinação de sementes, do crescimento de plantas, das bactérias fixadoras de nitrogênio e das nitrificantes (CASTRO; FERREIRA, 2001).

\section{CONCLUSÕES}

A planta de confrei, na forma de extrato bruto aquoso até 200 g.L. $\mathrm{L}^{-1}$ em casa de vegetação, não apresentou efeito inibitório sobre plantas de girassol, mas sim um estímulo a seu crescimento. Em laboratório, o extrato bruto aquoso de confrei em concentrações até $150 \mathrm{~g} \cdot \mathrm{L}^{-1}$ não apresentou efeito inibitório sobre a porcentagem de plântulas normais de girassol.

O extrato bruto aquoso de carqueja em concentração de 200 g. $\mathrm{L}^{-1}$ apresentou atraso da emergência de plantas de girassol em casa de vegetação. Em laboratório, houve interferência do uso do extrato bruto aquoso de carqueja sobre a ocorrếncia de anormalidade nas plântulas de girassol, comprovando um efeito significativo, mas sem tendência definida.

\section{REFERÊNCIAS}

BONA, C. M. et al. Carqueja: cultive esta idéia. Curitiba: SEAB-PR, 2002.

BO RKET, C. M. et al. E feito residual de adubação potássica sobre girassol e milho, em três diferentes latossolos roxos. Pesq. Agropec. Bras., Brasília, v. 32, n. 12, p. 1227-1234, 1997.

BRASIL. Ministério da agricultura e reforma agrária. Regras para análise de sementes. Brasília: SNAD / DNDV/ CLAV, 1992. 
CASTRO, L. O.; CHEMALE, V. M. Plantas medicinais, condimentares e aromáticas: descrição e cultivo. Guaíba: Agropecuária, 1995.

CASTRO, C. et al. A cultura do girassol. Londrina: EMBRAPA-CNPSo, 1997. (Circular Técnica, 13). CASTRO, H. G.; FERREIRA, F. A. Contribuição ao estudo das plantas medicinais (Baccharis genistelloides). Viçosa: Ed. UFV, 2001.

DEPINÉ, C. E feito alelopático de carqueja sobre a germinação de plantas daninhas. 2003. 43 f. Monografia (Bacharelado em Ciências Biológicas) - Núcleo de Ciências Biológicas e da Saúde. Centro Universitário Positivo, Curitiba, 2003.

FERREIRA, A. G.; ÁQUILA M. E. A. Alelopatia: uma área emergente da ecofisiologia. Rev. Bras. Fisiol. Veg., Brasília, v. 12, n. 2, p. 175-204, 2000.

TESKE, M.; TRENTINI, A. M. M. Compêndio de fitoterapia. 4. ed. Curitiba: Herbarium, 2001.

Recebido: $12 / 11 / 2007$

Received: $11 / 12 / 2007$

Aprovado: $05 / 04 / 2008$

A pproved: 04/05/2008

Revisado: 17/ 08/2009

Reviewed: 08/ 17/ 2009 